\title{
Effect of Cognitive Behavior Modification on Social Anxiety for High School Students
}

\author{
I-Jun Chen ${ }^{1 *}$, Chunxiang Du², Xiaoxiao Wang1, Hailun Zhang \\ ${ }^{1}$ School of Education, Soochow University, Suzhou, China \\ ${ }^{2}$ Suzhou Industrial Park NO.10 Middle School, Suzhou, China \\ Email: ^herbij@qq.com
}

How to cite this paper: Chen, I.-J., Du, C. X., Wang, X. X., \& Zhang, H. L. (2017). Effect of Cognitive Behavior Modification on Social Anxiety for High School Students. Creative Education, 8, 1803-1820. https://doi.org/10.4236/ce.2017.812124

Received: July 21, 2017

Accepted: September 22, 2017

Published: September 25, 2017

Copyright ( 92017 by authors and Scientific Research Publishing Inc. This work is licensed under the Creative Commons Attribution International License (CC BY 4.0).

http://creativecommons.org/licenses/by/4.0/

\section{Open Access}

\begin{abstract}
The authors of this study adopted an approach from cognitive behavior modification to design a SMART strategy, and applied the intervention to high school students. This study used a multiple baseline across-subject design to measure the degree of social anxiety among three high school students for the duration of 3 to 5 weeks, and then used the SMART strategy to intervene and document their mastering of strategies and changes of social anxiety for 15 weeks. Their anxiety level was measured and recorded 4 weeks after the intervention. The results showed that: 1) the SMART strategy can be effectively applied to high school students to address their social anxiety; 2) after the SMART strategy intervention, the students' social anxiety reduced instantly and significantly; 3) four weeks after the SMART strategy intervention, the intervention effect remained.
\end{abstract}

\section{Keywords}

Cognitive Behavior Modification, Social Anxiety, High School Students

\section{Introduction}

In recent years, the booming Chinese economy has led to intense opportunities and competitions. Such causing demands had increased employment pressure on many young people. Hence, intervention to support young generation's adaptation to their social development becomes critical to enhance their psychological well-being and quality of life. High school students face double psychological pressure in China, dealing not only with the intense stress of academic requirements for college entrance (Liu, 2006), but also psychological and physiological pressure of adolescenthood (Lou \& Chi, 2000). For instance, the rapid psychological and physiological changes in adolescence, especially issues related 
to their sexuality, may create additional social pressure when it comes to development of social relationship with peers. Under such pressure, their psychological issues worsen, especially anxiety, loneliness, fear, self-accusation and impulse (Xiao \& Shang, 2010; Zhang, 2012), of which social anxiety has become the prominent issue that affects the overall health of high school students (Hu et al., 2006; Yu et al., 2005).

Social anxiety refers to a noteworthy and lasting fear over one or more interpersonal plight (APA, 2013). Researchers found that social anxiety was the third worst problem that affected the psychological health of people, following $30.1 \%$ depression and $28 \%$ excessive drinking, which mostly took place during puberty (Gullone et al., 2001). Xiao et al. (2006) found that the prevalence of social anxiety for college and middle school students in Chengdu, China was $8.15 \%$. In comparison, as time progressed, $\mathrm{Li}$ (2012) found an increasing prevalence of social anxiety for middle school students in Hunan was $17.4 \%$. It can be seen that social anxiety is one of the serious psychological problems high school students confronting in China. High school students with social anxiety are mostly accompanied with negative emotion, such as fear, dread, shyness and awkwardness. These emotions can negatively impact their daily activities, academic performances and social interactions (Aderka et al., 2012; Chen et al, 2014; Yi et al., 2011). It is without doubt that families, schools and society should be concerned of the level of social anxiety among high school students.

Literature has shown that the intervention for social anxiety is mainly focused on psychological approaches (Acarturk et al., 2009; Heimberg \& Barlow, 1988; Yang et al., 2013). Previous studies proposed effective intervention techniques based on various theories, of which cognitive behavior modification (CBM) had been demonstrated the strongest evidence (Evans et al., 2008; Salovey \& Singer, 1991; Chang \& Chien, 2009). CBM strategy is also known as cognitive behavior modification technique (Swaggart, 1998; Yell et al., 2001; Chang \& Chien, 2006a), which covers principles from different theoretical backgrounds such as emotional therapy, cognitive therapy, behavioral therapy (Flannery-Schroeder \& Kendall, 2000), and humanistic psychology (Chang \& Chien, 2006b). CBM allows individuals to self-adjust through the cognitive process, in order to change certain improper behaviors (Zhang, 1989). It emphasizes the change and reconstruction of unreasonable thought processing. In other words, the inner cognitive activities constrain one's behavior, and as the cognitive activities be controlled and adjusted, changing unreasonable cognition could also alter one's behaviors and vice versa (Wang, 2000). CBM covers several strategies and techniques that enhance self-control capacity through the inner awareness of cognitive process and influence of behaviors on emotions. Specific CBM include problem-solving, anger control, self-instruction, alternate response, self-control, self-management, self-monitoring, self-awareness, self-evaluation and self-reinforcement (Swaggart, 1998; Yell et al., 2001).

Previous research suggested that the application of CBM could effectively 
change cognition, emotion and behavior of people (Chang \& Chien, 2009; Evans et al., 2008; Newman et al., 2000; Taylor et al., 2005). In particular, the self-instruction strategy generates intervention therapy effect for socially anxious students, thus significantly reducing anxiety and increasing positive self-dialogue and acceptance by companions (Masia et al., 2001). Another self-monitoring strategy is supported in terms of enhancing social skills and decreasing anxiety (Borkovec \& Ruscio, 2001; Briggs et al., 1980). There are scanty researches on self-reinforcement and self-awareness strategy at domestic and abroad, while most of them combined the use of self-instruction or self-monitoring (Hughes et al., 1991). Alberto and Troutman (1999) proposed that the majority of self-management steps emphasize the self-reinforcement and self-awareness strategy. Self-instruction refers to the psychological process through which individuals use the inner language to guide or normalize their own behavior or emotion (Chien, 2002). Self-monitoring allows individuals to self-evaluate whether their target behavior appears, thus elevating the individuals' self-awareness and reducing their emotional and behavioral problems (Nelson \& Hayes, 1981). Self-reinforcement enables students to enhance their proper behavior with inner language (Chang \& Chien, 2006b; Shapiro \& Cole, 1994). The psychological process of self-awareness is helpful for control of individual behaviors and emotions (Chen, 2003). To sum up, the four strategies mentioned above could effectively reduce anxiety and improve social skills.

Based on the analysis over the traits of social anxiety in high school students, the authors of this study developed SMART strategy using inner cognitive process techniques of self-instruction, self-monitoring, self-reinforcement and self-awareness, with an aim to help high school students self-monitor and overcome their social anxiety. The SMART strategy comprises five steps, which are represented by the five letters of SMART: 1) S (smile), meaning to confront with smiles; 2) M (monitoring), meaning to monitor one's own ideas, emotions and behaviors; 3) A (aware), meaning to be aware of current situation; 4) R (relax), meaning to regulate respiration and relieve nervousness; 5) $\mathrm{T}$ (think), meaning to think reasonably and positively. The five steps of the SMART strategy are made into separate indication cards so that participants can used the cues to remind themselves at anytime how to reconstruct cognition in order to monitor and control their level of social anxiety. The intervention period had four phases, including establishment of relationship and self-exploration, SMART strategy learning, SMART strategy consolidation, and review and summary, with the SMART strategy being used in the second and third phases.

This study aimed to investigate the students' use of the SMART strategy, and discussed the intervention effect of the strategy. The primary research question was "What is the effect of SMART strategy?". It was expected that after intervention, high school students' level of social anxiety would reduce. The following research questions were addressed:

1) Will the post-intervention scores of the Self-Evaluation Scale reduce com- 
pared to the pre-intervention conditions?

2) Will the post-intervention scores of the SMART Strategy Evaluation Scale reduce compared to the pre-intervention conditions?

3) Will the post-intervention scores of the SAQ-HSS reduce compared to the pre-intervention conditions?

\section{Method}

\subsection{Participants, Interventionist and Setting}

The participants of this study were three high school students with social anxiety without somatization symptom of social anxiety and were recommended by a public high school in Suzhou, China. The inclusion criteria was the score of Social Anxiety Questionnaire of High School Students (SAQ-HSS) (Wang, 2013) with 2 standard deviations higher than the average, and the somatization symptom factors of Symptom Checklist was 90 (SCL-90) (Derogatis, 1975), indicating less than 2. The researcher signed an inform consent with the participants and their parents, before intervention took place.

Hyman, a 17 years old boy, was scanty of words, and rarely participated in group activities. His teachers described him as having minimal interaction with his classmates in the classroom, keeping his head low most of the time, and rarely answering teachers' questions. Emily was a 17 years old girl, who indicated having social anxiety in many occasions, such as speaking in class, talking in front of family elderly, playing Guzheng in front of family guests, and making speeches on the platform. Her teachers described her as a hard-working student with excellent academic performance, but lacking confidence and failing to perform well in front of a large crowd. Cora was a 16 years old girl, who was shy, self-abased, and felt anxious when communicating with male counterparts. She also felt anxious when speaking with authorities. The scores of SAQ-HSS for the three participants were 4.04, 3.93 and 3.89 respectively $(M=2.647, S D=0.533)$, the somatization symptom factors in SCL-90 were less than 2 .

Both evaluation and intervention were conducted by the first author in a psychological consulting room at the attending school of the participants.

\subsection{Measures}

Symptom Checklist 90: The SCL-90 was filled out by each participant, in order to confirm that they had no somatization. This study selected the somatization factor of the scale as the research instrument. The somatization factor consists of ten items with a five-response scale ranging from never (0) to seriously (4). Scoring for this scale is conducted by totaling the individual responses to the ten items. Possible scores range from 0 to 4 . A higher score indicates a higher severity of the condition. Previous studies showed that the scale had reliable internal consistency reliability, and construct validity (Derogatis, 1975; Wang et al., 1999).

Self-Evaluation Scale: The Self-Evaluation Scale was developed by the au- 
thors and was filled out by the three participants in the psychological consulting room at the end of the first and third phases of the intervention period, so as to record the participants' level of anxiety. The evaluation content is the social anxiety scenarios filled out during the intervention period, such as classroom performance, talking with authorities, speaking publically, participating in class activities, and communicating with classmates. The scoring of the scale is from 0 to 9 points, whereas a higher score indicates stronger anxiety.

SMART Strategy Evaluation Scale: The authors of this study self-developed this scale. And it was filled out by the three participants at home within one week after the second, third, and fourth phases of the intervention period, so as to record the use of SMART strategy after the intervention. The content of the scale includes the use frequency of the five steps of the SMART strategy, with a four response scale ranging from never (0) to always (3). A higher score indicates more frequent use of the SMART strategy.

Social Anxiety Questionnaire of High School Students: The SAQ-HSS was recorded in the psychological consulting room in the three periods of baseline, intervention and follow-up by three individuals so as to measure the social anxiety conditions of participants. The content of the scale includes 28 items which are categorized into four factors of social sensitiveness, social avoidance, anxiety and nervousness, and social confidence. The questionnaire was scored on a 5 -point Likert scale ranging from $1=$ strongly disagree to $5=$ strongly agree. A higher score indicates stronger anxiety during social scenarios. The Cronbach's a values ranged between 0.64 and 0.89 for the subscales with the total score as 0.93 , indicating that the questionnaires achieved an acceptable level of reliability. The goodness-of-fit measures were: $\chi^{2}(N=1410)=1157.96(p=0.04), \mathrm{CMIN} / d f$ $=1.70<2.00$, GFI $=0.94>0.90, \mathrm{CFI}=0.94>0.90, \mathrm{TLI}=0.92>0.90, \mathrm{RMSEA}=$ $0.04<0.05$, indicating that the model had a highly satisfactory fit (Wang, 2013).

\subsection{Design}

This study adopted multiple baseline across-subject design to evaluate the use of the SMART strategy and change of social anxiety of high school students. This study included three periods of A, B and C, of which period A was the baseline period, B was the intervention period, and period $\mathrm{C}$ was the follow-up period. The three individuals were randomly allocated to the baseline period, the length of which was 3,4 , and 5 weeks respectively.

\subsection{Procedures}

Baseline: During the baseline period, the three participants filled out the SAQ-HSS once per week for three, four and five times respectively, in order to measure their baseline level of social anxiety.

Intervention: The intervention period for the three individuals was 15 weeks, once per week for 40 to 60 minutes in length. This study categorized the 15 sessions of intervention into four phases: 1) first phase (1st to 3rd sessions): estab- 
lishment of relationship and self-exploration; 2) second phase (4th to 5th sessions): strategic learning; 3 ) third phase (6th to 14th sessions): strategic consolidation; 4) fourth phase (15th session): review and summary. During the intervention, the participants filled out the SAQ-HSS once per week for 15 sessions in total.

Phase 1: Establishment of relationship and self-exploration. The intervention target of this phase was to establish a positive relationship between researcher and participants and help them conduct self-exploration. First, the researcher probed into the conditions of the participants through dialogues, and then introduced the objectives and process of the intervention. Second, the researcher guided the participants to self explore the social scenarios that they fear, the ideas that trigger anxiety, emotional state during anxiety, and alternative thoughts. Through the self-exploration, social scenarios that cause anxiety and related belief were explored, so as to enhance participants' cognitive reconstruction. In this process, the researcher summarized the anxious scenarios of the participants and developed a Self-Evaluation Scale. Finally, the participants were asked to fill out the Self-Evaluation Scale. After communicating with them to relieve their defense, they were willing to make correct evaluation on themselves.

Phase 2: SMART strategy learning. The intervention in this phase aimed to establish participants' familiarity and application of the SMART strategy. First, the researcher introduced the content of SMART strategy in details. Then, the researcher demonstrated the use of the strategy. Finally, through role-playing, the researcher and the participants practiced the use of the strategy following simulated social scenarios. In this process, the participants seemed lost, and did not know what to do.

Phase 3: SMART strategy consolidation. This phase was the application phase of SMART strategy, consisting six steps.

Step 1: Identify emotion and face with smile (6th session). This step emphasized on the practice of S strategy, which aimed to enable the participants to identify emotions and face social scenarios with a smile. S strategy mainly used self-instruction strategy. First of all, the researcher demonstrated the performance in the anxious scenarios, and then the participants gave a performance in the scenarios, so as to identify others' and their own emotions. Then, the researcher asked the participants to draw their possible emotional states and their target emotional states under social scenarios on the emotion face book. Lastly, the researcher taught the participants to remind themselves to a smile in nervous social scenarios and express their target emotion.

Step 2: Self-monitoring and self-control (7th and 8th sessions). This step emphasized on the practice of $\mathrm{M}$ strategy, which aimed to teach the participants to monitor their emotion, idea and behavior under social scenarios. $M$ strategy mainly employed self-monitoring strategy. Above all, exposure exercise, such as scenario simulation and role-playing, were conducted, so as to enable the participants to control their own ideas and behavioral change under social scena- 
rios. Secondly, the participants practiced deep breath and relaxation, and wrote down their behaviors and ideas monitored throughout the process.

Step 3: Self-awareness and self-acceptance (9th and 10th sessions). This step emphasized on the practice of A strategy, which aimed to teach the participants to be aware of and accept oneself. A strategy employed the self-awareness strategy. Firstly, the researcher played a piece of soft music, and asked the participants to walk barefooted on the floor and feel the breath in the music. Then, the researcher asked the participants to imagine the nervous and anxious scenarios last week, as well as their ideas, thoughts and physical feeling under such scenarios. They integrated their feeling into breathing each time. In the end, the music stopped, and the participants sat down to share their views and feelings with the researcher.

Step 4: Self-relaxation to enhance confidence (11th and 12th sessions). This step emphasized on the practice of R strategy, which aimed to teach the participants to adjust their breath adjustment and adopt self-instruction when feeling nervous and anxious, in order to enhance confidence and relieve nervous emotion. R strategy mainly employed self-instruction strategy. To begin with, the researcher simulated the social scenarios selected by the participants. The participants regulated their breath and relaxed for preparation, then loudly spoke out the positive self-instruction words. Then, the participants were asked to practice with the researcher aloud, and the voice gradually waned into the internal self-instruction. The researcher provided feedback during the practice. Eventually, the participants were asked to employ the inner language to conduct self-instruction under anxious scenarios.

Step 5: Positive thinking to encourage oneself (13th session). This step emphasized on the practice of T strategy, which aimed to teach the participants to reduce negative remarks in social scenarios, correctly resolve problems during social intercourse, so as to encourage and affirm them. T strategy mainly employed self-instruction and self-reinforcement strategies. For one thing, the researcher gave affirmation and praise to the participants on their performances in the past phases, and guided them to correctly solve problems occurred in this process. Then, the researcher asked the participants to evaluate their own performances in social scenarios, gave encouragement and hints, while minimizing negative remarks. Lastly, the researcher asked the participants to write down the positive remarks on the paper, and pasted it onto a glittering tree. The participants gained confidence in social intercourse as they saw the positive remarks on the tree.

Step 6: Smile and keep head up to respond calmly (14th session). This step aimed to comprehensively practice the SMART strategy, in order to enhance the participants' social skills. For a start, the participants were asked to choose one out of two pictures of smile and smiling eyes, and explain their choice. They were then asked to show a proper smile and eye expression in the social scenarios. In this process, the researcher gave instructions and feedback. Then, the re- 
searcher observed the participants' walking posture in the imagined social scenarios, and guided them to walk confidently and asked them to compare the difference. As the social scenarios were imaginary, the participants still need to practice their skills in actual social scenarios.

Phase 4: review and summary. This phase was to review the process and evaluated the changes (15th session). The researcher asked the participants to describe the changes they felt during the intervention process. And to further understand the willing of participants adopt the SMART strategy in the future for hints and adjustment to improve their social skills.

\subsection{Follow-up}

Four weeks after the end of intervention (i.e., the 5th week after the intervention), the participants were followed up for additional 3 weeks. In the follow-up period, the three participants filled out the SAQ-HSS for 3 consecutive weeks.

\section{Results}

The authors of this study investigated the self-evaluation of three participants under social scenarios, and the scores of the SMART Strategy Evaluation Scale and the SAQ-HSS to evaluate the level of high school students' social anxiety. The results indicated the high school students could actively use the strategies and the social anxiety level effectively reduced.

\subsection{Self-Evaluation Scale}

The results of the Self-Evaluation Scale regarding to three participants are showed in Figure 1. As compared to the pre-intervention conditions, the post-intervention social anxiety levels of the three participants has been reduced by different degrees in class performance, talking to authorities, speaking publically, participating in class activities and communicating with classmates. It can be suggested from these results that the SMART strategy has considerable effect in reducing of social anxiety.

\subsection{SMART Strategy Evaluation Scale}

Figure 2 depicts the average score of the three participants in the use of various steps of the SMART strategy. All three participants adopted the SMART strategy, and the use frequency of $S, R$ and $T$ strategies were relatively higher. Except for the frequency of using $\mathrm{T}$ strategy by Cora was lower than 2 points, the frequency of using $\mathrm{S}, \mathrm{R}$ and $\mathrm{T}$ strategies by the three participants were over 2 points, and frequency of using $\mathrm{S}$ and $\mathrm{R}$ strategies by Emily even reached 2.5 points. Apart from the frequency of using A strategy by Hyman was slightly lower than 1 point, the frequency of using $\mathrm{M}$ and $\mathrm{A}$ strategies by the three participants were all around 1.5 points (i.e., the frequency of using $\mathrm{M}$ and A strategies were between occasionally often). Therefore, in general, the mastering of strategies was positive, suggesting that the participants could actively use the 


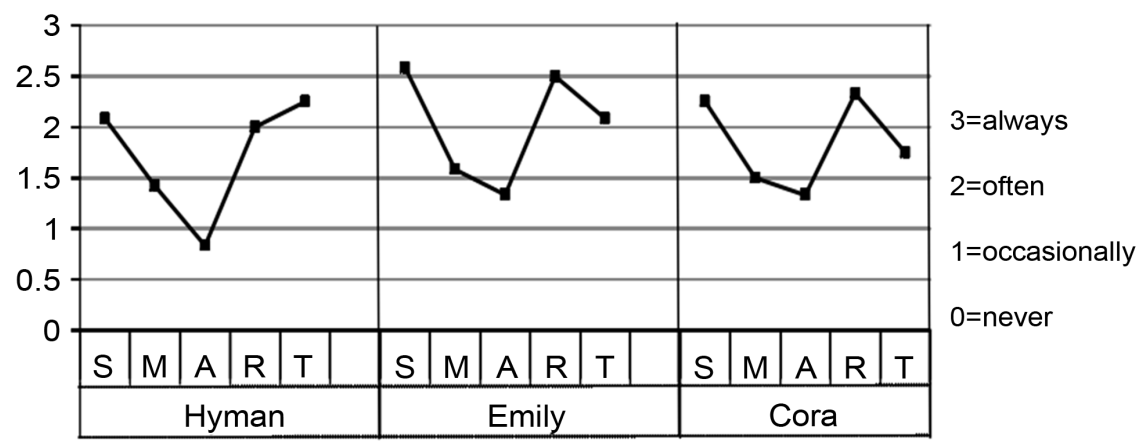

Figure 1. The level of social anxiety for Hyman (left panel), Emily (center panel), and Cora (right panel) in five kinds of situations. $\mathrm{A}=$ classroom performance; $\mathrm{B}=$ talking to authorities; $\mathrm{C}=$ speaking publicly; $\mathrm{D}=$ participating in class activities; $\mathrm{E}=$ communicating with classmates.

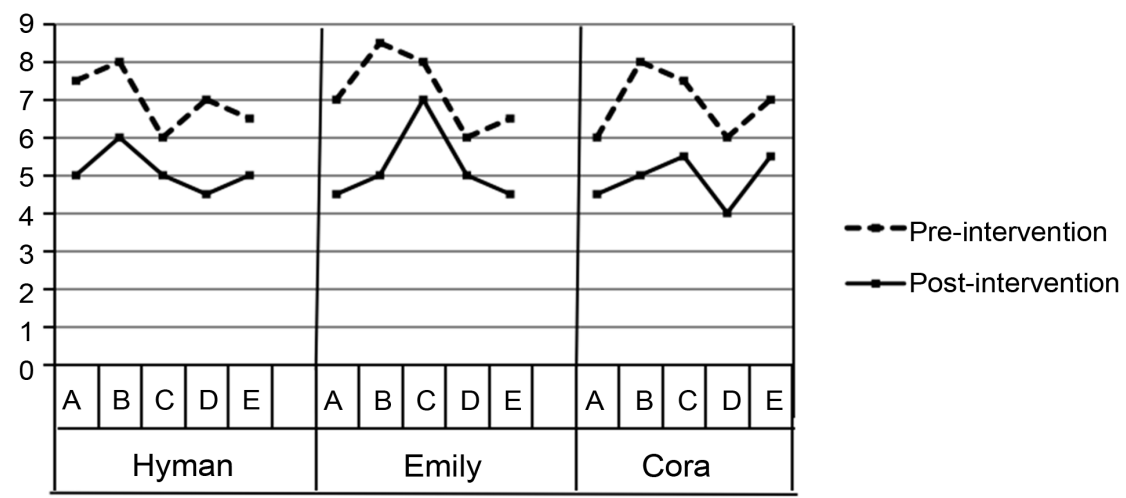

Figure 2. The use frequency of SMART strategy for Hyman (left panel), Emily (center panel), and Cora (right panel).

strategies during the intervention and practice in daily life.

\subsection{Social Anxiety Questionnaire of High School Students}

The Figure 3 illustrates the scores of the SAQ-HSS under different experimental periods and the features of multiple baseline across-subject design. After the three participants were sequentially exposed to the experimental conditions, their social anxiety levels were reduced and the effect was remained same until the follow-up period. The specific analysis is as follows: the social anxiety level of the three participants was relatively stable in the baseline period, while Hyman and Emily were slightly fluctuated. After the SMART strategy intervention, the social anxiety level gradually decreased and was apparently lower than the baseline period led to stable change. The social anxiety level of Cora was slightly fluctuated during the middle of intervention. In the follow-up period, although the social anxiety level increased slightly than the intervention period and was lower than baseline and pre-intervention periods showing stable status (Figure 3).

\subsection{Changes in Social Anxiety for Hyman}

As shown in Table 1, the scores of the SAQ-HSS for Hyman in the baseline pe- 


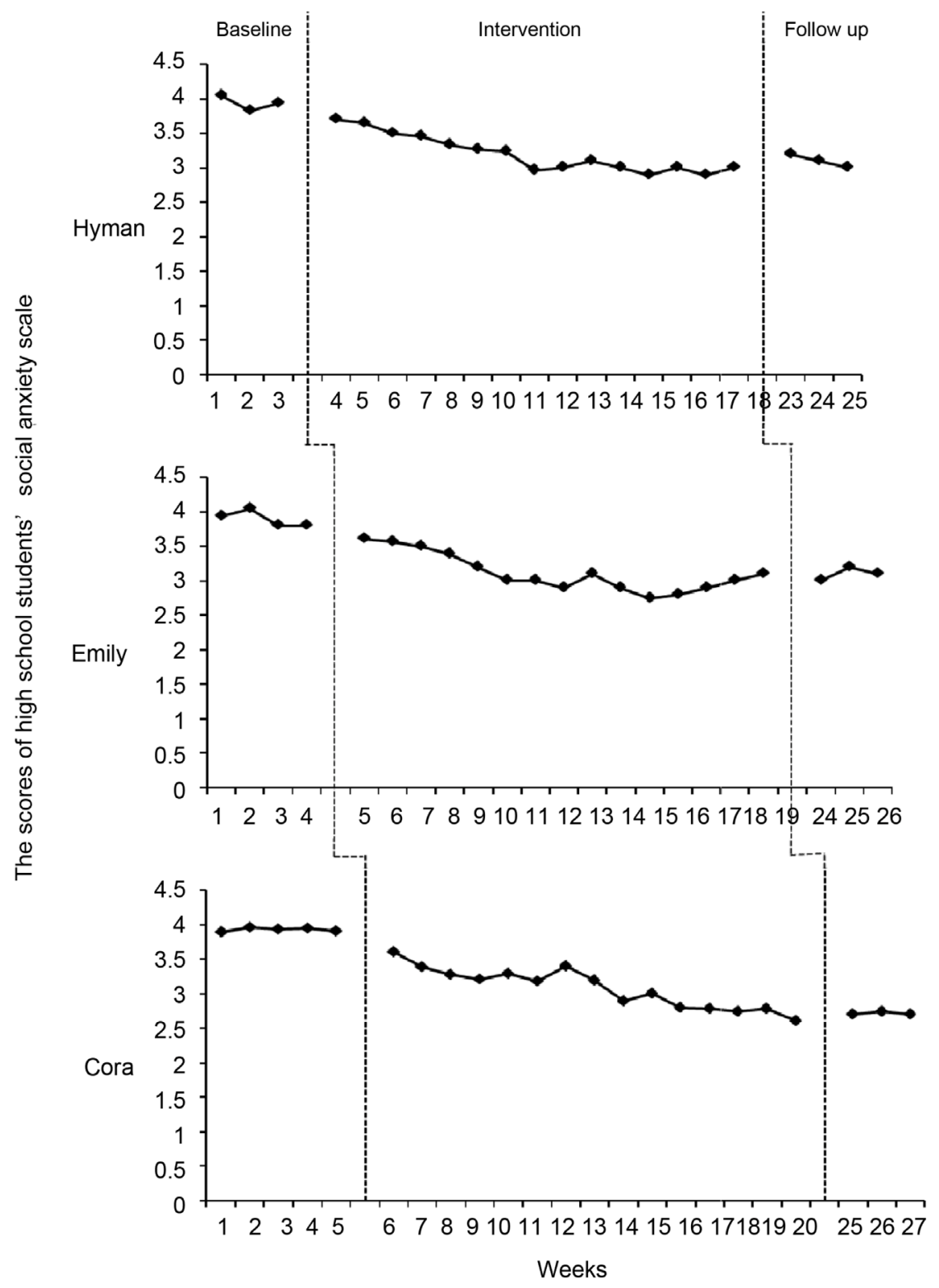

Figure 3. Scores of social anxiety scale of senior high school students for Hyman (upper panel), Emily (center panel), and Cora (lower panel) across baseline, intervention, and follow-up.

riod were between 3.82 and 4.04, with an average score of 3.93. The score showed a decreasing trend, and the tendency stability was $100 \%$ (the proportion of data points within the average range of $15 \%$ in the period), in other words, all the data points fell within the $15 \%$ range of the average value of 3.93 . Therefore, the invention began from the 4th week, and the SMART strategy training was introduced for intervention. During the intervention period, Hyman's score of SAQ-HSS were between 2.89 and 3.70, with an average score of 3.20, showing a decreasing trend, and the tendency stability was $100 \%$. As shown in Table 2, the tendency from the baseline period to the intervention period changed negatively, and the overlap proportion (the percentage of data points which fell in the range 
Table 1. Abstract table for change of scores of the SAQ-HSS for the three participants within the three periods.

\begin{tabular}{|c|c|c|c|c|c|c|c|c|c|}
\hline $\begin{array}{l}\text { Participant } \\
\text { Period }\end{array}$ & \multicolumn{3}{|c|}{ Hyman } & \multicolumn{3}{|c|}{ Emily } & \multicolumn{3}{|c|}{ Cora } \\
\hline Sequence of period & A & B & $\mathrm{C}$ & A & B & $\mathrm{C}$ & A & B & $\mathrm{C}$ \\
\hline Length of period & 3 & 15 & 3 & 4 & 15 & 3 & 5 & 15 & 3 \\
\hline \multicolumn{10}{|l|}{ Tendency } \\
\hline Tendency stability & $100 \%$ & $100 \%$ & $100 \%$ & $100 \%$ & $100 \%$ & $100 \%$ & $100 \%$ & $93.33 \%$ & $100 \%$ \\
\hline Range & $3.82-4.04$ & $2.89-3.70$ & $3.00-3.20$ & $3.79-4.04$ & $2.75-3.60$ & $3.00-3.10$ & $3.89-3.96$ & $2.60-3.60$ & $2.70-2.75$ \\
\hline Average value & 3.93 & 3.20 & 3.10 & 3.89 & 3.11 & 3.10 & 3.93 & 3.08 & 2.72 \\
\hline Anxiety level & $4.04-3.93$ & $3.70-3.00$ & $3.20-3.00$ & $3.93-3.80$ & $3.60-3.10$ & $3.00-3.10$ & $3.89-3.90$ & $3.60-2.60$ & $2.70-2.70$ \\
\hline Variation & -0.11 & -0.70 & -0.20 & -0.13 & -0.50 & 0.10 & 0.01 & -1.00 & 0.00 \\
\hline
\end{tabular}

$\mathrm{A}=$ baseline period; $\mathrm{B}=$ intervention period; $\mathrm{C}=$ follow-up period.

Table 2. Abstract table for change of scores of SAQ-HSS for the three participants between the three periods.

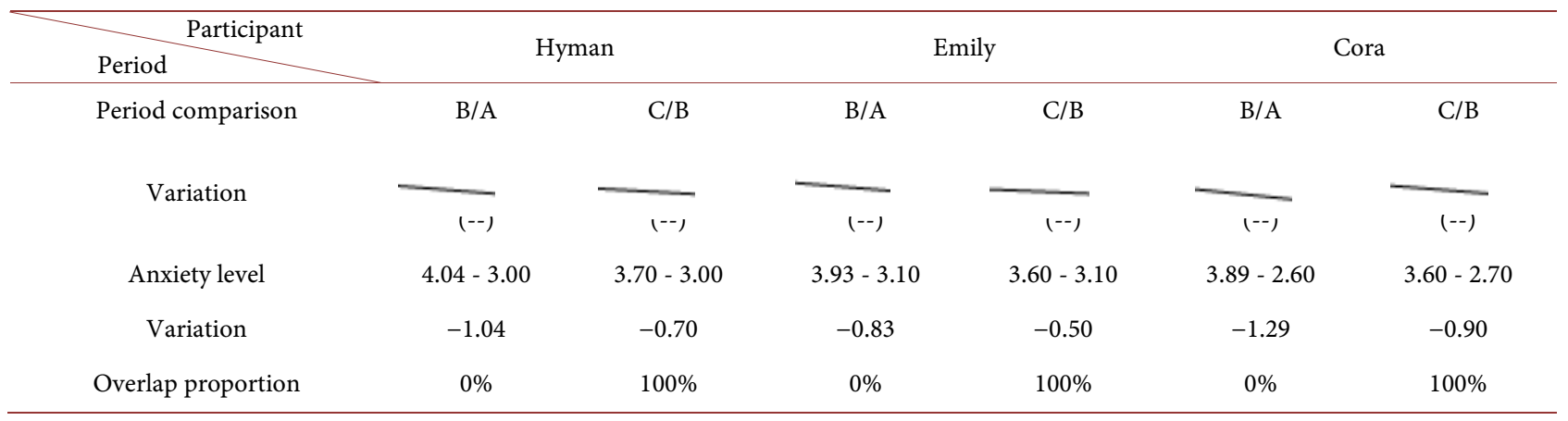

$\mathrm{A}=$ baseline period; $\mathrm{B}=$ intervention period; $\mathrm{C}=$ follow-up period.

of previous-period data points) was $0 \%$, suggesting that the SMART strategy effectively reduced Hyman's social anxiety level. According to Table 1, Hyman's social anxiety in the follow-up period was between 3.00 and 3.20, with an average score of 3.10. The score showed a decreasing trend, and the tendency stability was $100 \%$. Table 2 lists that the average value in the follow-up period was lower than that of the intervention period, and the overlap proportion was $100 \%$. Even though there was a 4 weeks interval, the intervention effects still maintained.

Based on the above data analysis in the baseline, intervention and follow-up periods, it can be seen that after Hyman received the SMART strategy training, his social anxiety level reduced significantly, and the effect lasted even after 4 weeks.

\subsection{Changes in Social Anxiety for Emily}

Table 1 listed that the scores of the SAQ-HSS for Emily in the baseline period were between 3.79 and 4.04, with an average score of 3.89. The score showed a decreasing trend, and the tendency stability was $100 \%$, suggesting that all the 
data points fell within the $15 \%$ of the average value of 3.89 . Thus, the SMART strategy training was introduced for intervention. During the intervention period, Emily's social anxiety scores were between 2.75 and 3.60, with an average score of 3.11. The score showed a decreasing trend, and the tendency stability was $100 \%$. According to Table 2, the tendency from the baseline period to the intervention period changed negatively, and the overlap proportion was $0 \%$, suggesting that the SMART strategy positively reduced Emily's social anxiety level. As shown in Table 1, Emily's social anxiety scores in the follow-up period were between 3.00 and 3.10, with an average score of 3.10. The score showed a decreasing trend, and the tendency stability was $100 \%$. Table 2 shows that the average value in the follow-up period was lower than that of the intervention period, and the overlap proportion was $100 \%$, indicating that the intervention effect of SMART strategy on Emily lasted in the follow-up period.

Based on the above data analysis in the baseline, intervention and follow-up periods, it can be seen that after Emily received SMART strategy training, her social anxiety level was reduced significantly, and the effect lasted significantly.

\subsection{Changes in Social Anxiety for Cora}

It can be seen from Table 1 that the scores of SAQ-HSS for Cora in the baseline period were between 3.89 and 3.96, with an average score of 3.93. The score showed a decreasing trend, and the tendency stability was $100 \%$. Thus, the SMART strategy training was introduced for intervention. In the intervention period, Cora's social anxiety scores were between 2.60 and 3.60, with an average score of 3.08. The score showed a decreasing trend, and the tendency stability was $93.33 \%$. As shown in Table 2, the tendency from the baseline period to the intervention period changed negatively, and the overlap proportion was $0 \%$, indicating that the SMART strategy significantly reduced Cora's social anxiety level. According to Table 1, Cora's social anxiety scores in the follow-up period were between 2.70 and 2.75, with an average score of 2.72 . The score showed a decreasing trend, and the tendency stability was $100 \%$. Table 2 shows that the average value in the follow-up period was lower than that of the intervention period, and the overlap proportion was $100 \%$, suggesting that in the follow-up period, Cora's social anxiety level showed a declining trend as compared to the intervention period.

Based on the above data analysis in the baseline, intervention and follow-up periods, it can be seen that after Cora received the SMART strategy training, her social anxiety level was reduced, and the intervention effect obviously lasted over 4 weeks.

\section{Discussion}

The authors of this study utilized CBM to address high school students' social anxiety. The self-evaluation of the participants in the five social scenarios included class performance, talking to authorities, speaking publically, participat- 
ing in class activities, and communicating with classmates. The results of this study indicated that the implementation of SMART strategy had positively effects on the level of social anxiety among the participants. During intervention, the authors helped the participants practice the strategy under simulated scenarios. The selection of social scenarios was made according to the anxiety scenarios described by the participants in the self-exploration period, and the key content of the strategy was chosen for practice, in order to improve the use extent of CBM and the social anxiety level. Researches regarding social anxiety showed that exposure practice could effectively improve the social anxiety of individuals (Hofmann et al., 2006; Tian, 2010). Wu, Ye, and She (2011) pointed out that repeated exposure practice could reduce the fear and withdrawal of individuals in social scenarios, increasing their social activities. Due to the restriction of conditions, this study only conducted imaginary exposure practice, which asked the participants to imagine the social scenarios and feeling being there. They then applied the SMART strategy to overcome their anxiety. This approach allowed the researcher to guide the participants to effectively master the SMART strategy. When they were in real scenarios, the participants could adeptly employ the strategy so as to better control their emotion and behavior in the on-site exposure practices. Through the imaginary exposure practice in the intervention period and the practice in real scenario at home, the participants practiced their skills in the use of the strategy, and reduced the social anxiety level to some extent.

The scores of the SMART Strategy Evaluation Scale showed that the participants generally mastered the SMART strategy well. The usage frequency of S, R and $\mathrm{T}$ strategies was high, as indicated as "often" and "always" by the participants in their use evaluation. The use of $\mathrm{M}$ and A strategies was lower than the former three, possibly because the cognitive behavior modification strategy in $\mathrm{S}, \mathrm{R}$ and $\mathrm{T}$ strategies were easier to master, such as the self-instruction and self-reinforcement strategies. On the other hand, the self-monitoring and self-awareness strategies were not so easily mastered within a short time. The use of the above strategies improved the social anxiety conditions of the participants to a great extent, which was mentioned in previous studies. Self-instruction strategy has been widely applied in different fields, such as improving the behavioral disorder and emotional problems of students. Researches showed that the self-instruction training could help students to improve their social and emotional problems (Mooney et al., 2005; Webber et al., 1993). Chen (2011) found that social anxiety and self-monitoring were significantly correlated. Estow, Jamieson, and Yates (2007) found that students with a high degree of self-monitoring were more apt to simulate active target behavior. The use of strategy is critical to the intervention effect, and is an important indicator to examine the intervention effect. As self-monitoring and self-awareness strategies were rather difficult to apply, future studies can enhance the guidance and practice over these strategies, so as to better improve the overall intervention effect. 
This study plotted the score curves and tabulated the in-period and between-period variation tables based on the scores of SAQ-HSS of high school students. The results showed that CBM has instant effect and better continuous effect in terms of reducing the social anxiety level of high school students. This finding is consistent with existing research results. Taylor et al. (2005) suggested that training on self-instruction, self-monitoring and cognitive reconstruction could effectively help aggressive children to control their emotions, and the cognitive behavior modification strategy is influential on emotional change. Chang and Chien (2009) combined the self-instruction and self-monitoring strategies (COOL strategy) to form cognitive behavior modification strategy, in order to intervene the children with learning disorder. They suggested that the strategy could help children to effectively control their emotions and the intervention effect could be retained for a long time.

Some researches found that individuals with social anxiety have negative cognitive characteristics, such as having obvious subjective anxiety experience, objective avoidance and fear of being rejected. Those with high-degree of social anxiety are highly concerned about others' opinions and impressions on them (Yao et al., 2008). Wilson and Rapee (2005) found that when individuals with social anxiety were interpreting negative events, they tended to believe that these events would result in negative remarks of others, and would signify that they have negative personality traits, bringing detrimental consequences to their interpersonal relationship and social performance. Those with social anxiety tended to exaggerate the interpretation over the severity of scenarios, lack confidence over their coping capacity and tolerance for frustration, and have negative self-statement and self-defeat ideas. Therefore, considering the features of those with social anxiety, this study developed four strategies, namely self-instruction, self-awareness, self-monitoring and self-reinforcement, in order to help effectively reducing the anxiety level of high school students.

There are several potential limitations of this study that warrant discussion. First, the results of this study showed that the mastering of self-monitoring and self-awareness strategies in the SMART strategy were not as successful as the mastering of self-instruction and self-reinforcement. Hence, future studies could pay more attention to the teaching and practice of the self-instruction and self-reinforcement strategies in future intervention planning. Second, this study failed to obtain diversified data regarding social intercourse in real life, such as the performance of the participants in real social life. Our omission of such data is a potential limitation and direction for future research. Third, this study failed to employ exposure practice due to constraints in the intervention, but used the imaginary exposure practice, which allowed the participants to imagine the social scenarios, felt being there at the moment, and applied the SMART strategy to overcome anxiety. Although this study employed the imaginary exposure practice, the results showed that the social anxiety level of the three participants reduced. Future studies could compare the effect of the two. Finally, this study 
employed multiple baseline across-subject design, and conducted experiments on only three participants. It was a small-sample exploratory research that could not make convincing inference as the research with large quantity samples. Future studies could use the SMART strategy, and conduct experiments on small groups or large teams, in order to verify its feasibility in team application.

The SMART strategy for the three recruited high school students was developed based on the CBM with culturally relevant social scenarios through imaginary exposure practice, which may have a greater potential to address Chinese adolescent's social anxiety. Future researches could evaluate the use frequency (or dosing) of SMART strategy in the follow-up period, in order to identify whether the application of the strategy may have a carry-over effect. Since self-monitoring and self-awareness were outside the scope of this research, future studies could create a detailed monitoring record in order to better evaluation its efficacy. Moreover, the social situation of participants in real life could be evaluated from the aspects of parents, teachers and peers in order to allow opportunities for further program development and evaluation.

\section{Conclusion}

The SMART strategy can be effectively applied to high school students to address their social anxiety instantly as well as significant to intervention effects.

\section{Acknowledgements}

The authors are profoundly grateful to the three high school students, whose participation made this research possible, and to the high school in Suzhou, China that provided support concerning participate and setting aspects. Support was provided by the programming foundation of ministry of education, humanities and social science research projects in China (14YJA880009) and the "twelfth five-year" programming of science of education in Jiangsu province, China (B-b/2011/01/038).

\section{References}

Acarturk, C., Cuijpers, P., Van, S. A., \& De, G. R. (2009). Psychological Treatment of Social Anxiety Disorder: A Meta-Analysis. Psychological Medicine, 39, 241-254. https://doi.org/10.1017/S0033291708003590

Aderka, I. M., Hofmann, S. G., Nickerson, A., Hermesh, H., Gilboa-Schechtman, E., \& Marom, S. (2012). Functional Impairment in Social Anxiety Disorder. Journal of Anxiety Disorders, 26, 393-400. https://doi.org/10.1016/j.janxdis.2012.01.003

Alberto, P. A., \& Troutman, A. C. (1999). Applied Behavior Analysis for Teachers (5th ed.). Upper Saddle River, NJ: Merrill/Prentice-Hall.

American Psychiatric Association (APA) (2013). Diagnostic and Statistical Manual of Mental Disorders (5th ed.) (DSM-V). Arlington, VA: American Psychiatric Publishing. https://doi.org/10.1176/appi.books.9780890425596

Borkovec, T. D., \& Ruscio, A. M. (2001). Psychotherapy for Generalized Anxiety Disorder. Journal of Clinical Psychiatry, 62, 37-45.

Briggs, S. R., Cheek, J. M., \& Buss, A. H. (1980). An Analysis of the Self-Monitoring Scale. 
Journal of Personality and Social Psychology, 38, 679-686.

https://doi.org/10.1037/0022-3514.38.4.679

Chang, M. H., \& Chien, J. L. (2006a). The Application of Cognitive Behavioral Strategies in the Adjustment of Teachers' Work Pressure in Inclusive Education. In National Taichung University of Education (Ed.), Special Education Series (pp. 67-80). Taichung: The National Taichung University of Education Press.

Chang, M. H., \& Chien, J. L. (2006b). The Application of Intuitive Teaching in Adjusting Stress for Teachers. Elementary School Special Education, 42, 29-39.

Chang, M. H., \& Chien, J. L. (2009). The Effect of a Cognitive Behavior Modification Strategy for Elementary School Students with Learning Disabilities on Aggressive Behavior. Journal of Special Education, 30, 51-91.

Chen, J. Y. (2003). Self-Awareness in the Counseling: The Self-Awareness Supervision Model. Research in Applied Psychology, 18, 59-87.

Chen, Y. J., Chen, C., Wei, B. S., Yu, Q., \& Han, X. (2014). Influential Factors of Anxiety and Behavioral Problems among Children with Learning Difficulties. Chinese Journal of Public Health, 30, 853-857.

Chen, Z. B. (2011). A Study on the Relationship of Social Anxiety, Self-Monitoring and Self-Disclosure. Science of Social Psychology, 26, 148-151.

Chien, J. L. (2002). The Effect of a Cognitive Behavior Modification Strategy on On-Task Behavior. Dissertation Abstracts International, 63, 4202.

Derogatis, L. R. (1975) How to Use the Systom Distress Checklist (SCL-90) in Clinical Evaluations, Psychiatric Rating Scale. In R. L. Derogatis (Ed.), Self-Report Rating Scale (pp. 22-36). Hoffmann-La Roche Inc.

Estow, S., Jamieson, J. P., \& Yates, J. R. (2007). Self-Monitoring and Mimicry of Positive and Negative Social Behaviors. Journal of Research in Personality, 41, 425-433.

Evans, S., Ferrando, S., Findler, M., Stowell, C., Smart, C., \& Haglin, D. (2008). Mindfulness-Based Cognitive Therapy for Generalized Anxiety Disorder. Journal of Anxiety Disorders, 22, 716-721.

Flannery-Schroeder, E. C., \& Kendall, P. C. (2000). Group and Individual Cognitive-Behavioral Treatments for Youth with Anxiety Disorders: A Randomized Clinical Trial. Cognitive Therapy and Research, 24, 251-278. https://doi.org/10.1023/A:1005500219286

Gullone, E., King, N. J., \& Ollendick, T. H. (2001). Self-Reported Anxiety in Children and Adolescents: A Three-Year Follow-Up Study. The Journal of Genetic Psychology, 162, 5-19. https://doi.org/10.1080/00221320109597878

Heimberg, R. G., \& Barlow, D. H. (1988). Psychosocial Treatments for Social Phobia. Psychosomatics, 29, 27-37.

Hofmann, S. G., Meuret, A. E., Smits, J. A., Simon, N. M., Pollack, M. H., Eisenmenger, K., Otto, M. W. et al. (2006). Augmentation of Exposure Therapy with D-Cycloserine for Social Anxiety Disorder. Archives of General Psychiatry, 63, 298-304. https://doi.org/10.1001/archpsyc.63.3.298

Hu, C. M., Guo, Y., \& Yu, K. (2006). Study Concerning the Relationship between High School Students' Independent Learning Ability and Mental Health. Education Exploration, No. 11, 94-96.

Hughes, C. A., Korinek, L., \& Gorman, J. (1991). Self-Management for Students with Mental Retardation in Public School Settings: A Research Review. Education and Training in Mental Retardation, 26, 271-291.

Li, L. (2012). The Research for the High School Student's Features of Social Anxiety and the Relationship among Social Anxiety and the Related Variables. Unpublished Mas- 
ter's Thesis, Changsha: Hunan University.

Liu, H. F. (2006). The Nature and Phenomena of College Entrance Examination Competition. Journal of Higher Education, 27, 27-31.

Lou, W. Q., \& Chi, I. (2000). The Stressors and Psychological Well-Being of Senior Secondary School Students. Psychological Science, 23, 156-159.

Masia, C. L., Klein, R. G., Storch, E. A., \& Corda, B. (2001). School-Based Behavioral Treatment for Social Anxiety Disorder in Adolescents: Results of a Pilot Study. Journal of the American Academy of Child \& Adolescent Psychiatry, 40, 780-786. https://doi.org/10.1097/00004583-200107000-00012

Mooney, P., Ryan, J. B., Uhing, B. M., Reid, R., \& Epstein, M. H. (2005). A Review of Self-Management Interventions Targeting Academic Outcomes for Students with Emotional and Behavioral Disorders. Journal of Behavioral Education, 14, 203-221. https://doi.org/10.1007/s10864-005-6298-1

Nelson, R. O., \& Hayes, S. C. (1981). Theoretical Explanations for Reactivity in Self-Monitoring. Behavior Modification, 5, 3-14. https://doi.org/10.1177/014544558151001

Newman, B., Reinecke, D. R., \& Meinberg, D. L. (2000). Self-Management of Varied Responding in Three Students with Autism. Behavioral Interventions, 15, 145-151. https://doi.org/10.1002/(SICI)1099-078X(200004/06)15:2<145::AID-BIN50>3.0.CO;2-3

Salovey, P., \& Singer, J. A. (1991). Cognitive Behavior Modification. In F. H. Kanfer, \& A. P. Goldstein (Eds.), Helping People Change: A Textbook of Methods (4th ed., (pp. 361-395). Elmsford, NY: Pergamum Press.

Shapiro, E. S., \& Cole, C. L. (1994). Behavior Change in the Classroom: Self-Management Interventions. London: Guilford Press.

Swaggart, B. L. (1998). Implementing a Cognitive Behavior Management Program. Intervention in School and Clinic, 33, 235-238.

https://doi.org/10.1177/105345129803300406

Taylor, J. L., Novaco, R. W., Gillmer, B. T., Robertson, A., \& Thorne, I. (2005). Individual Cognitive-Behavioral Anger Treatment for People with Mild-Borderline Intellectual Disabilities and Histories of Aggression: A Controlled Trial. British Journal of Clinical Psychology, 44, 367-382. https://doi.org/10.1348/014466505X29990

Tian, Y. L. (2010). The Intervention of Cognitive Behavior Therapy for High School Students with Social Anxiety. Unpublished Master's Thesis, Yangzhou: Yangzhou University.

Wang, J. S., Li, Y., \& He, E. S. (1999). Development of SCL-90 in Secondary School Students. Chinese Mental Health Journal, 13, 8-10.

Wang, X. J. (2000). The Review of Cognitive-Behavioral Therapy. Studies in Dialectics of Nature, 16, 25-28.

Wang, X. X. (2013). The Effect of Cognitive Behavior Modification Strategy for High School Students with Social Anxiety. Unpublished Master's Thesis, Soochow: Soochow University.

Webber, J., Scheuermann, B., McCall, C., \& Coleman, M. (1993). Research on Self-Monitoring as a Behavior Management Technique in Special Education Classrooms: A Descriptive Review. Remedial and Special Education, 14, 38-56. https://doi.org/10.1177/074193259301400206

Wilson, J. K., \& Rapee, R. M. (2005). The Interpretation of Negative Social Events in Social Phobia: Changes during Treatment and Relationship to Outcome. Behavior Re- 
search and Therapy, 43, 373-389.

Wu, M. H., Ye, X. H., \& She, Y. Y. (2011). Application of Cognitive Behavioral Group Therapy for Patients with Social Anxiety Disorder. Nursing and Rehabilitation Journal, 10, 187-189.

Xiao, R., Wu, D. L., Hu, J. M., Qiu, C. J., Wang, Q., Wei, G., Zhang, W. et al. (2006). Prevalence and Incidence of Influencing Factors Analysis of Social Anxiety Disorder in High Schools and Universities in Chengdu City. Journal of Sichuan University (Medical Science Edition), 37, 636-640.

Xiao, Y. J., \& Shang, H. R. (2010). Investigation on the Psychological Anxiety of High School Students of Provincial Secondary School in Tianhe District of Guangzhou City. Soft Science of Health, 24, 435-438.

Yang, W., Yu, Z. F., \& Wang, Y. (2013). A Case of Metacognition Psychological Intervention of College Student's Social Anxiety. Science of Social Psychology, 28, 118-120.

Yao, Y., Yu, J., \& Chen, B. P. (2008). The Relationship between the Cognition Character and the Parental Rearing Pattern in Social Anxiety Disorder. China Journal of Health Psychology, 5, 553-554.

Yell, M. L., Robinson, T. R., \& Drasgow, E. (2001). Cognitive Behavior Modification. In T. J. Zirpoli, \& K. J. Melloy (Eds.), Behavior Management: Applications for Teachers (pp. 200-246). Upper Saddle River, NJ: Merrill/Prentice Hall.

Yi, Y. H., Li, Y. B., \& Xie, J. S. (2011). Investigation and Analysis on the Social Anxiety in the Countryside in Hunan Province. Educational Measurement and Evaluation, No. 1, $39-42$.

Yu, Y. Y., Liang, X. F., Zhao, G. X., Lin, Z. Y., \& Yang, X. (2005). Investigation of Mental Health Status and Influencing Factors Analysis in Senior Middle School Students in Xinhui District of Jiangmen City. Chinese Journal of Clinical Rehabilitation, 9, 22-24.

Zhang, C. X. (1989). Zhang Dictionary of Psychology. Shanghai: Shanghai Lexicographical Publishing House.

Zhang, J. (2012). The Relationship of Loneliness and Family Function in High School Students. Chinese Journal of Public Health, 28, 688-689.

Submit or recommend next manuscript to SCIRP and we will provide best service for you:

Accepting pre-submission inquiries through Email, Facebook, LinkedIn, Twitter, etc. A wide selection of journals (inclusive of 9 subjects, more than 200 journals)

Providing 24-hour high-quality service

User-friendly online submission system

Fair and swift peer-review system

Efficient typesetting and proofreading procedure

Display of the result of downloads and visits, as well as the number of cited articles

Maximum dissemination of your research work

Submit your manuscript at: http://papersubmission.scirp.org/

Or contact ce@scirp.org 